\title{
Clostridium difficile cure with fecal microbiota transplantation in a child with Pompe disease: a case report
}

\author{
D. E. Dow ${ }^{1 *}$ and P. C. Seed ${ }^{2}$
}

\begin{abstract}
Background: Recurrent Clostridium difficile infection is a growing problem among children due to both the increasing survival of medically fragile children with complicated chronic medical conditions resulting in prolonged antibiotic exposure and hospitalization and the emergence of strains of Clostridium difficile that are hypervirulent and associated with high rates of relapse.

Case presentation: This case describes a medically complex 21-month-old Hispanic girl with Pompe disease and B cell immunodeficiency with recurrent Clostridium difficile infection refractory to antimicrobial management. She presented with nine recurrent episodes of Clostridium difficile infection including fever, foul smelling diarrhea, and respiratory distress with failed sustained responses to compliant treatment using metronidazole and pulsed vancomycin therapy. Maternal donor fecal microbiota transplantation was performed with complete symptom resolution and produced a sustained cure, now 5 years in duration.

Conclusions: This patient presented with symptomatic Clostridium difficile at an early age causing significant morbidity and reduced quality of life. After nearly one year of failed medical management, fecal microbiota transplantation provided a cure. Further evidence-based research is necessary to test the safety and efficacy of this low technology, low cost, and morbidity-sparing therapy in children.
\end{abstract}

Keywords: Refractory Clostridium difficile, Fecal microbiota transplantation, Medically complex children

\section{Background}

Clostridium difficile infection (CDI) has been steadily increasing among children over the last decade [1-4], resulting in increased hospitalizations, morbidity, and cost $[5,6]$. The factors that account for this increasing incidence are not entirely understood, but include the emergence of the hypervirulent and multidrug-resistant $C$. difficile strain, NAP1/BI/027 [7, 8], the strain DH/NAP11/106 [9] which is associated with high rates of relapse, and the increasing survival of children with complicated chronic medical conditions that result in increased antibiotic exposure and prolonged hospitalization.

C. difficile is a Gram-positive, anaerobic, sporeforming bacterium. It is acquired through the fecal-oral route, traditionally during exposure to the health care

\footnotetext{
* Correspondence: dorothy.dow@duke.edu

${ }^{1}$ Division of Infectious Diseases, Department of Pediatrics, Duke University

Medical Center, Box 3499, Durham, NC 27710, USA

Full list of author information is available at the end of the article
}

environment, though it is increasingly recognized to be acquired in the community $[1,2,10]$. $C$. difficile persists in the environment and on home and hospital surfaces for months to years and resists many methods of elimination [11]. The pathogenesis of CDI begins with disruption of the normally diverse intestinal microbiota, which establishes nutritional niches and metabolic pathways that prevent colonization of $C$. difficile and other pathogens in a healthy host. Antibiotics can alter this homeostatic environment leading to colonic dysbiosis that predisposes the host to pathogenic bacteria, such as $C$. difficile. Sporulation and germination of $C$. difficile leads to exotoxin A (TcdA) and exotoxin B (TcdB) production that have cytotoxic and proinflammatory effects on the gastrointestinal epithelium [12]. Without an adequate immune response, CDI symptoms may include diarrhea, leukocytosis, fever, abdominal pain, and pseudomembranous colitis, and can progress to toxic megacolon 
requiring abdominal surgery such as colectomy, septic shock, and even death $[6,13]$.

Established risk factors for CDI include antibiotic exposure, prolonged hospitalization, bowel manipulation, or surgery including gastrointestinal feeding devices and immunosuppression $[6,8,14]$. Not all antibiotics pose the same risk for CDI; clindamycin and cephalosporins, along with fluoroquinolones and penicillins pose the greatest risk, presumably producing specific disruptions in microbiota homeostasis that open new niches for $C$. difficile to flourish [15]. The medical necessity for recurrent antibiotic exposure, feeding devices, and hospitalizations among medically complex children create a persistent risk state for recurrent CDI once infection is established.

Treatment guidelines and a pediatric-specific policy statement are published for CDI $[15,16]$. Goals of therapy are shared by both publications and include discontinuation of inciting antibiotic therapy, or narrowing the antibiotic spectrum if antibiotics are necessary to treat an underlying condition. Metronidazole remains the drug of choice for initial mild infections; orally administered vancomycin, although more expensive and increasing the risk of vancomycin-resistant Enterococcus species infection, is indicated for severe infections, even if they are the first occurrence [17]. CDI recurrence is generally defined as new CDI within 8 weeks, or up to 12 weeks for children, after onset and resolution of the previous episode $[15,18]$. Data suggest once there is a first recurrence, patients are $35-40 \%$ more likely to have a second recurrence, $[19,20]$ and have a $60 \%$ risk after a second recurrent CDI $[21,22]$. In children, $30 \%$ have recurrence of infection either from the same strain, or exposure to a new strain [8]. The first relapse is treated with the same drug as initial infection depending on disease severity; use of metronidazole is not recommended beyond two courses due to potential neurotoxicity. For multiple recurrences, tapered/pulsed orally administered vancomycin, rifaximin, nitazoxanide, or fidaxomicin have been used but without specific evidence to support the practice [8]. Probiotics such as Saccharomyces boulardii have modest utility [15]. In refractory cases, fecal microbiota transplantation (FMT) involving instillation of stool from a healthy donor to restore the indigenous enterome has provided higher rates of cure than traditional antibiotic therapy [19].

\section{Case presentation}

A 21-month-old Hispanic girl born full term via cesarean was diagnosed as having cross-reactive immunologic material negative (CRIM-negative) Pompe disease at 4 months of age. Her disease was complicated by dilated cardiomyopathy, ventilator dependence, and failure to thrive requiring primary nutrition by a gastrojejunostomy (GJ) feeding tube. At 6 months of life, she initiated alglucosidase alfa therapy and treatment to limit immune rejection of the enzyme therapy with rituximab and methotrexate, eliciting a B cell immunodeficient state. At 9 months of life, she presented with recurrent foul-smelling diarrhea, fever, and abdominal discomfort while receiving broad-spectrum antibiotics (piperacillin/ tazobactam) for presumed aspiration pneumonia based on her initial symptoms of cough and fever. The diagnosis of CDI was confirmed by polymerase chain reaction (PCR) for C. difficile toxin and exclusion of other infectious etiology. Her CDI was treated with metronidazole with symptom resolution and subsequent negative PCR for toxin; however, her symptoms and positive PCR continued to recur soon after cessation of antibiotic therapy (Table 1). With each new recurrence, she presented with fever, diarrhea, and decompensated with respiratory distress, hospital admission, and use of systemic antibiotics; a recurrent cycle leading to significant morbidity and reduced quality of life.

After 12-months of recurrent CDI, four courses of metronidazole, and one short course of vancomycin followed by two rounds of tapered vancomycin therapy, she continued to experience symptoms of fever, foul smelling diarrhea, and respiratory distress. FMT was presented as an alternative therapy. The child's biological mother, originally from El Salvador, was screened to be the fecal donor using a previously described protocol [23]. Her mother, a previously healthy woman of normal body

Table 1 Timeline of recurrent Clostridium difficile infection and treatment strategies

\begin{tabular}{|c|c|c|}
\hline Recurrence & $\begin{array}{l}\text { Confirmatory positive } \\
\text { C. difficile PCR }\end{array}$ & Treatment \\
\hline & February 10, 2010 & Metronidazole $\times 7$ days \\
\hline 1 & March 10, 2010 & Metronidazole $\times 7$ days \\
\hline 2 & April 8, 2010 & Metronidazole $\times 10$ days \\
\hline 3 & May 20, 2010 & Metronidazole $\times 10$ days \\
\hline 4 & June 7, 2010 & $\begin{array}{l}\text { Orally administered } \\
\text { vancomycin } \times 10 \text { days }\end{array}$ \\
\hline 5 & July 3, 2010 & $\begin{array}{l}\text { Orally administered } \\
\text { vancomycin } \times 6 \text { weeks } \\
\text { with taper }\end{array}$ \\
\hline 6 & November 10, 2010 & \multirow{2}{*}{$\begin{array}{l}\text { Orally administered } \\
\text { vancomycin } \times 6 \text { weeks } \\
\text { with taper }\end{array}$} \\
\hline 7 & December 2, 2010 & \\
\hline 8 & December 31, 2010 & $\begin{array}{l}\text { approached for fecal } \\
\text { microbial transplant }\end{array}$ \\
\hline 9 & February 21, 2011 & $\begin{array}{l}\text { Fecal microbiota transplant } \\
\text { February 24, } 2011\end{array}$ \\
\hline None & $\begin{array}{l}\text { All subsequent PCR } \\
\text { negative to date } \\
\text { (last PCR sent } \\
\text { April 2, 2016) }\end{array}$ & \\
\hline
\end{tabular}

$P C R$ polymerase chain reaction 
habitus, had no history of parasitic infections, typhoid fever, or dysentery, no recent antibiotic use, no immunosuppressant drug use, no metabolic disorders, and no history of colonic polyps or cancers. Laboratory testing included screening for human immunodeficiency virus (HIV), hepatitis A, hepatitis B, hepatitis C, rapid plasma reagin (RPR), and Trypanosoma cruzi serologies which were all negative. A complete blood count and complete metabolic profile were within normal limits. Two separate stool samples were screened: by culture for enteric pathogens including Giardia, Cryptosporidium, and Yersinia; for $C$. difficile toxin by PCR; and for ova and parasites at 3 weeks and 1 week prior to transplant. All studies were negative.

Five days prior to transplant our patient's symptoms reappeared, and vancomycin was initiated $(40 \mathrm{mg} / \mathrm{kg}$ per day divided each 6 hours), her parents agreed to a signed consent for fecal transplantation. On the day of transplant, our patient was afebrile, her vital signs were stable with weight of $12 \mathrm{~kg}$ on respiratory ventilation, and her physical examination was within normal limits for her baseline. The freshly donated maternal stool sample weighed $11 \mathrm{~g}$ and was homogenized with $100 \mathrm{~mL}$ normal saline. The stool was then filtered through sterile gauze and a coffee filter to remove all significant particulate matter. Our patient's longstanding GJ tube was accessed and flushed with $15 \mathrm{ml}$ of saline through the jejunal inlet; $35 \mathrm{ml}$ of the stool filtrate was then administered, followed by $15 \mathrm{ml}$ normal saline flush without complication, all within approximately 4 hours of the sample donation. Her vital signs were measured prior to the transplant and every 30 minutes for 2 hours after the transplant. She was discharged home with instructions to resume regular feeds and medications. Orally administered vancomycin was discontinued. To date (5-years postfecal transplant), our patient remains PCR negative for $C$. difficile toxin and free of CDI symptoms. She experienced no adverse events attributable to FMT.

\section{Discussion}

FMT has been only rarely utilized and reported among children with recurrent CDI. This case is unusual due to this child's underlying genetic disease, immunodeficiency, and 5-year follow-up documenting a durable medical cure. This patient had several risk factors for CDI including immunocompromised state, frequent ongoing exposure to the health care environment, administration of broad-spectrum antibiotics, feeding via GJ feeding tube, and cesarean delivery. The continuous cycle of refractory CDI resulted in repeat hospital admissions and the use of broad-spectrum antibiotics, which led to treatment with FMT. The goal of FMT was to correct the underlying colonic dysbiosis and to reestablish the diverse fecal flora that acts as a host defense against $C$. difficile $[19,24,25]$. The availability of the maternal donor to restore the fecal microbial homeostasis of her child was ideal.

Controversy exists over when a child may develop CDI. Infants under 12 months have some of the highest known colonization rates, up to $50 \%$ depending on duration of hospitalization and breast versus formula feeding [26-29]. Prior research posited that infants lack the molecular machinery or toxin receptors to process $C$. difficile toxin [30]. Infants may not experience true symptomatic disease which occurs when exotoxin is produced and internalized in intestinal epithelial cells causing inflammation and cell death [16, 31, 32]. More recent work suggested that the transition from colonization to disease may reside in the immune response to $C$. difficile [33]. This patient was immunosuppressed while receiving rituximab and methotrexate and presented with symptoms suggestive of recurrent CDI.

Early, small cohort, prospective, randomized controlled trials of FMT established up to $90 \%$ efficacy and safety among adults and superiority to orally administered vancomycin $[19,21,34,35]$; however, to date, no randomized controlled trials among children have been published. FMT using more patient and family accepted methods of delivery have led to development and testing of mass-produced, orally ingested capsules [21, 34]. Given the significant economic burden of recurrent CDI [36], FMT offers a potentially cost-effective and efficacious therapy to cure recurrent CDI in children as demonstrated in this report.

The limitations of this single case report include the young age at which this patient became symptomatic, the lack of strain typing for the hypervirulent NAP1/ $\mathrm{BI} / 027$ and the strain DH/NAP11/106 which is associated with high rates of relapse, and lack of clonal analysis. We do not have microbiome level data from our patient or from her mother to demonstrate the preFMT or post-FMT community composition; however, symptom resolution and disappearance of toxin suggest the FMT did successfully supplant the $C$. difficile-associated microbiota with a more homeostatic state resistant to recurrent CDI.

\section{Conclusions}

This report demonstrated that FMT may be safely and effectively employed in a medically complex child, although the risk-benefit relationship of recurrent CDI and FMT complications must be currently weighed on an individual basis. Evidence-based, randomized controlled trials are urgently needed to evaluate the safety and efficacy of this procedure in children. 


\section{Abbreviations}

CDI: Clostridium difficile infection; FMT: Fecal microbiota transplantation; GJ : Gastrojejunostomy; PCR: Polymerase chain reaction

\section{Acknowledgements}

The authors would like to thank the patient and her family for their willingness to undergo FMT and encouraging the publication of this case.

\section{Funding}

This project was done with no specific support of funding.

\section{Availability of data and materials}

Data sharing is not applicable to this article as no datasets were generated or analyzed during the current study. Data supporting the results are extracted from the patient's medical file.

\section{Authors' contributions}

DED was the fellow on the case and synthesized the case findings, laboratory tests, and treatment and drafted the case report. PCS was the attending physician on the case and helped in revision of the case report. Both authors read and approved the final manuscript.

\section{Ethics approval and consent to participate}

The Duke Institutional Review Board (IRB) waived requirement for ethical approval of this case report.

\section{Consent for publication}

Written informed consent was obtained from the patient's legal guardian for publication of this case report and any accompanying images. A copy of the written consent is available for review by the Editor-in-Chief of this journal.

\section{Competing interests}

The authors declare that they have no competing interests.

\section{Publisher's Note}

Springer Nature remains neutral with regard to jurisdictional claims in published maps and institutional affiliations.

\section{Author details}

${ }^{1}$ Division of Infectious Diseases, Department of Pediatrics, Duke University Medical Center, Box 3499, Durham, NC 27710, USA. ²Division of Infectious Diseases, Department of Pediatrics, Feinberg School of Medicine, Northwestern University, Evanston, USA.

\section{Received: 1 March 2017 Accepted: 20 March 2018} Published online: 28 April 2018

\section{References}

1. Kim J, Smathers SA, Prasad P, Leckerman KH, Coffin S, Zaoutis T. Epidemiological features of Clostridium difficile-associated disease among inpatients at children's hospitals in the United States, 2001-2006. Pediatrics. 2008:122(6):1266-70.

2. Benson L, Song X, Campos J, Singh N. Changing epidemiology of Clostridium difficile-associated disease in children. Infect Control Hosp Epidemiol. 2007;28(11):1233-5.

3. Zilberberg MD, Shorr AF, Kollef MH. Increase in Clostridium difficile-related hospitalizations among infants in the United States, 2000-2005. Pediat Infect Dis J. 2008;27(12):1111-3.

4. Deshpande A, Pant C, Anderson MP, Donskey CJ, Sferra TJ. Clostridium difficile infection in the hospitalized pediatric population: increasing trend in disease incidence. Pediatr Infect Dis J. 2013:32(10):1138-40.

5. Sammons JS, Localio R, Xiao R, Coffin SE, Zaoutis T. Clostridium difficile infection is associated with increased risk of death and prolonged hospitalization in children. Clin Infect Dis. 2013;57(1):1-8.

6. Tschudin-Sutter S, Tamma PD, Naegeli AN, Speck KA, Milstone AM, Perl TM Distinguishing community-associated from hospital-associated Clostridium difficile infections in children: implications for public health surveillance. Clin Infect Dis. 2013:57(12):1665-72.

7. McDonald LC, Killgore GE, Thompson A, Owens RC Jr, Kazakova SV, Sambol SP, Johnson S, Gerding DN. An epidemic, toxin gene-variant strain of Clostridium difficile. N Engl J Med. 2005;353(23):2433-41.
8. Tamma PD, Sandora TJ. Clostridium difficile Infection in Children: Current State and Unanswered Questions. J Pediatr Infect Dis Soc. 2012;1(3):230-43.

9. Kociolek LK, Patel SJ, Shulman ST, Gerding DN. Molecular epidemiology of Clostridium difficile infections in children: a retrospective cohort study. Infect Control Hosp Epidemiol. 2015;36(4):445-51.

10. Kim J, Shaklee JF, Smathers S, Prasad P, Asti L, Zoltanski J, Dul M, Nerandzic M, Coffin SE, Toltzis P, et al. Risk factors and outcomes associated with severe Clostridium difficile infection in children. Pediatr Infect Dis J. 2012; 31(2):134-8.

11. Weaver L, Michels HT, Keevil CW. Survival of Clostridium difficile on copper and steel: futuristic options for hospital hygiene. J Hosp Infect. 2008;68(2): 145-51.

12. Sun $X$, Hirota SA. The roles of host and pathogen factors and the innate immune response in the pathogenesis of Clostridium difficile infection. Mol Immunol. 2015:63(2):193-202.

13. Rao K, Young VB. Fecal microbiota transplantation for the management of Clostridium difficile infection. Infect Dis Clin N Am. 2015:29(1):109-22.

14. Crews JD, Koo HL, Jiang ZD, Starke JR, DuPont HL. A hospital-based study of the clinical characteristics of Clostridium difficile infection in children. Pediatr Infect Dis J. 2014;33(9):924-8.

15. Cohen SH, Gerding DN, Johnson S, Kelly CP, Loo VG, McDonald LC, Pepin J, Wilcox MH, Society for Healthcare Epidemiology of America, Infectious Diseases Society of America. Clinical practice guidelines for Clostridium difficile infection in adults: 2010 update by the society for healthcare epidemiology of America (SHEA) and the infectious diseases society of America (IDSA). Infect Control Hosp Epidemiol. 2010;31(5):431-55.

16. Schutze GE, Willoughby RE, Committee on Infectious Diseases, American Academy of Pediatrics. Clostridium difficile infection in infants and children. Pediatrics. 2013;131(1):196-200

17. Zar FA, Bakkanagari SR, Moorthi KM, Davis MB. A comparison of vancomycin and metronidazole for the treatment of Clostridium difficileassociated diarrhea, stratified by disease severity. Clin Infect Dis. 2007; 45(3):302-7

18. Kociolek LK, Patel SJ, Shulman ST, Gerding DN. Concomitant Medical Conditions and Therapies Preclude Accurate Classification of Children With Severe or Severe Complicated Clostridium difficile Infection. J Pediatr Infect Dis Soc. 2015;4(4):e139-42.

19. van Nood E, Vrieze A, Nieuwdorp M, Fuentes S, Zoetendal EG, de Vos WM Visser CE, Kuijper EJ, Bartelsman JF, Tijssen JG, et al. Duodenal infusion of donor feces for recurrent Clostridium difficile. N Engl J Med. 2013;368(5): 407-15.

20. McDonald LC, Coignard B, Dubberke E, Song X, Horan T, Kutty PK, Ad Hoc Clostridium difficile Surveillance Working Group. Recommendations for surveillance of Clostridium difficile-associated disease. Infect Control Hosp Epidemiol. 2007;28(2):140-5.

21. Khanna S, Pardi DS, Kelly CR, Kraft CS, Dhere T, Henn MR, Lombardo MJ Vulic M, Ohsumi T, Winkler J, et al. A Novel Microbiome Therapeutic Increases Gut Microbial Diversity and Prevents Recurrent Clostridium difficile Infection. J Infect Dis. 2016:214(2):173-81.

22. Vardakas KZ, Polyzos KA, Patouni K, Rafailidis PI, Samonis G, Falagas ME. Treatment failure and recurrence of Clostridium difficile infection following treatment with vancomycin or metronidazole: a systematic review of the evidence. Int J Antimicrob Agents. 2012;40(1):1-8.

23. Russell G, Kaplan J, Ferraro M, Michelow IC. Fecal bacteriotherapy for relapsing Clostridium difficile infection in a child: a proposed treatment protocol. Pediatrics. 2010;126(1):e239-42.

24. Gough E, Shaikh H, Manges AR. Systematic review of intestinal microbiota transplantation (fecal bacteriotherapy) for recurrent Clostridium difficile infection. Clin Infect Dis. 2011:53(10):994-1002.

25. Kassam Z, Lee $\mathrm{CH}$, Yuan Y, Hunt RH. Fecal microbiota transplantation for Clostridium difficile infection: systematic review and meta-analysis. Am J Gastroenterol. 2013:108(4):500-8.

26. Cooperstock M, Riegle L, Woodruff CW, Onderdonk A. Influence of age, sex, and diet on asymptomatic colonization of infants with Clostridium difficile. J Clin Microbiol. 1983;17(5):830-3.

27. Bolton RP, Tait SK, Dear PR, Losowsky MS. Asymptomatic neonatal colonisation by Clostridium difficile. Arch Dis Child. 1984;59(5):466-72.

28. Larson HE, Barclay FE, Honour P, Hill ID. Epidemiology of Clostridium difficile in infants. J Infect Dis. 1982;146(6):727-33.

29. Al-Jumaili IJ, Shibley M, Lishman $\mathrm{AH}$, Record $\mathrm{CO}$. Incidence and origin of Clostridium difficile in neonates. J Clin Microbiol. 1984;19(1):77-8. 
30. Eglow R, Pothoulakis C, Itzkowitz S, Israel EJ, O'Keane CJ, Gong D, Gao N, Xu YL, Walker WA, JT LM. Diminished Clostridium difficile toxin A sensitivity in newborn rabbit ileum is associated with decreased toxin A receptor. J Clin Invest. 1992:90(3):822-9.

31. Borriello SP. 12th C. L. Oakley lecture. Pathogenesis of Clostridium difficile infection of the gut. J Med Microbiol. 1990;33(4):207-15.

32. Kelly CP, Kyne L. The host immune response to Clostridium difficile. J Med Microbiol. 2011;60(Pt 8):1070-9.

33. El Feghaly RE, Stauber JL, Tarr PI, Haslam DB: Intestinal inflammatory biomarkers and outcome in pediatric Clostridium difficile infections. J Pediatr 2013, 163(6):1697-1704 e1692.

34. Youngster I, Russell GH, Pindar C, Ziv-Baran T, Sauk J, Hohmann EL. Oral, capsulized, frozen fecal microbiota transplantation for relapsing Clostridium difficile infection. JAMA. 2014;312(17):1772-8.

35. Gerding DN, Meyer T, Lee C, Cohen SH, Murthy UK, Poirier A, Van Schooneveld TC, Pardi DS, Ramos A, Barron MA, et al. Administration of spores of nontoxigenic Clostridium difficile strain M3 for prevention of recurrent C. difficile infection: a randomized clinical trial. JAMA. 2015;313(17): 1719-27.

36. Ghantoji SS, Sail K, Lairson DR, DuPont HL, Garey KW. Economic healthcare costs of Clostridium difficile infection: a systematic review. J Hosp Infect. 2010;74(4):309-18

Submit your next manuscript to BioMed Central and we will help you at every step:

- We accept pre-submission inquiries

- Our selector tool helps you to find the most relevant journal

- We provide round the clock customer support

- Convenient online submission

- Thorough peer review

- Inclusion in PubMed and all major indexing services

- Maximum visibility for your research

Submit your manuscript at www.biomedcentral.com/submit
Biomed Central 